\title{
Elementos Arquetípicos em A NEBULOSA de Joaquim Manuel de Macedo
}

Este trabalho faz parte da pesquisa realizada de 1976 a 1979, na Universidade de Indiana, Bloomington, EUA; na Blblloteca Nacional e no Instituto Histórico e Geográfico do Rlo de Janeiro, com o objetivo de realizar - levantamento de toda a obra de Joaquim Manuel de Macedo. Disso resultou, também, a dissertação de Mestrado, Contradição e ConciHaço na obra de Joaquim Manuel de Macedo. 


\section{Introdução}

A Nebulosa, de Joaquim Manuel de Macedo, é um poema narrativo, de conteúdo melodramático, segundo os moldes e temas do ultra-romantismo de inspiração byroniana. ${ }^{1}$ Composto em versos decassilados brancos, divide-se em seis cantos e üm epilogo que apresentam os seguintes assuntos :e pérsonagens:

Canto I - A Rocha Negra: descriçăo do cenấio amaldiçoado em que se desenrolará a tragédia amorosa de um misterioso bardo, denominado o Trovador, que vaga pelos penhascos à beira-mar:

.Súbito aparecendo e.inesperado, Nunca mais se arredou daquela enseada;

... Em vão refere o velho o caso infausto

$\therefore \quad$ Da Nebulosia: mal o atende e foge

O Trovador incrédulo ou sem medo:

Ave das noltes nas desoras vela;

Rei dos penhascos tem seu trono erguido

Na rocha-negra; esconde-se dos homens,

$E$ ou nefanda traição tornou-lhe 0 mundo

Em báratro fatal, ou crime horrendo

Envolto em feio crepe aos olhos todos,

Ele, algoz de si mesmo, oculta n'alma

Qu'a um tempo asila o crime e os seus remorsos.

Não quer consolações, que as não procura

E sombrio volvendo o olhar sinistro

Pelo mar, sobre a rocha, ou fundo vale,

1. Uttllzamos, nesse trabalho, duas ediçóes do poema: a $1 \%$, de 1857, da Typographia Im. e Const. de J. Villeuneuve e C., Rlo de Janeiro; e a nova ediçäo, s. d., de H. Garnier, Livrelro-editor, Rio de Janeiro. Sobre o exito do poema e suas caracteristicas lelam-se: MARTINS, Wilson. História da inteligência brasileira, Vol. III, Sq̊o Paulo, Cultrlx, 1977, p. 52-54. WOr.F, Ferdinand - o Brasll literário (illstoria de literatura braslleira), såo Paulo, Companhia Editora Naclonal, 1955, p. 286-289. 
Como que busca, onde melhor o espere

Mudo jazigo do eternal descanso.2

Segundo uma tradição, o penhásco negro conservaria poderosos influxos atribuídos a uma formosa feiticeira, a Nebulosa, que, por castigo divino; se têria precipitado ao mar, ao esquecer-se de pronunciar as satânicas palavras de cabala, as quais lhe davam o poder de pairar entre o céu e a terra, como um anjo das trevas.

A este lugar sombrio costuma recolher-se o atormentado Trovador, que, acompanhado de sua harpa, lamenta sua desdita amorosa e maldiz a vida.

Sua solidão, entretanto, é quebrada: do mar tenebroso, em fantástico batel, vem a seu encontro uma jovem, apelidada de a Douda, que se acredita consagrada à Nebulosa.

Canto II - Douda: a bela e estranha jovem, que chega atraída pela música do Trovador, conta-lhe sua histórla: tinha sido destinada ao culto da Nebulosa, quando era ainda criança. Como prova, mostra ao poeta a nódoa que the mancha a testa - sinal e estigma do pacto estabelecido entre sua mãe e a feiticeeira. A Nebulosa, rainha das magas, tendo visto a miséria e o abandono em que viviam a Douda e a mãe; prometera-lhes proteção e o conhecimento da arte mágica. Em troca, exigia que ambas, mäe e filha, lhe prestassem eterno culto.

"- Por que choras? ...

Meiga pergunta; e minha mãe responde:

"-Choro as misérias de uma vida ingrata;

"Trabalho um ano pra comer um dial

"Mirrados tenho já maternos seios;

"Vai morrer minha flllha."

2. MACEDO, Joaquim Manoel. A Nebulosa, Rio de Janelro, Typographia Imp. e Const. de J. Villeneuve e C., 1857, pp. 11-12. 


\begin{abstract}
"- A Nebulosa
Olhar de tigre em minha mãe cravando, "Faz-lhe a fronte curvar e a enleia toda; E enfim the torna:

"- Mudarei teu fado!

"Sou das magas rainha; em corpo e alma "Mãe e filha a meu culto consagradas "Terão em paga proteção de génios, "E dos encantos tenebroso ensino; "Vê se te agrada".3
\end{abstract}

O Destino da Douda, depois da morte, seria habitar o palácio da Nebulosa - reino das fadas e lugar vedado aos homens.

Pressentindo a maldição que também determina a sorte do Trovador, a Douda solidariza-se com ele, em mal dissimulada paixão.

Fora atraída pelo som da harpa - a que dá o nome de amor que fala - assim, pede ao Trovador que cante para ela, no momento em que deverá juntar-se à Nebulosa, no fundo do mar, a fim de cumprir o pacto funesto.

O Trovador e a Douda trocam confidências: ela conhece a desdita amorosa do Trovador e o estigma de um jamais, proferido por uma mulher inacessivel, que determinara a sorte do bardo, na vida e no amor. A Douda confessa que também ama com desespero, subjugada pela eterna lei do amor, a que ninguém pode subtrair-se, nem mesmo a Nebulose.

O Trovador narra sua desventura: apaixonado por uma mulher insensivel, abandonara a mãe viúva $\mathrm{e}$, seguindo os conselhos de uma feiticeira, fora em busca de glórias guerreiras e artisticas. Tudo se revelara inútil: nem os louros

3. MACEDO, op. cit. p. 50 
obtidos com a espada, nem os louros alcançados com a sua lira conseguiram demover a virgem cruel. Sempre recebla um jamais como resposta. Sabe-se, então, que a conselheira fora a mãe da Douda; por isso, a moça sempre pudera acompanhar a história das tristezas e súplicas do Trovador.

O poeta, finalmente, implora à Douda que lhe dé algum filtro mágico para alcançar o amor que the é negado. Embora sofrendo muito, porque 0 ama, a Douda promete ajudé-lo.

Canto III - A Peregrina: a Douda, após muito angustiar-se e refletir, decide procurar a mulher amada pelo Trovador. Atravessando montanhas e florestas, chega a um recanto paradisíaco onde depara com a bela dame sans merci, conhecida pelo nome de Peregrina. A beleza dessa mulher quase sobrenatural, fascina a todos - a própria Douda conclui que Peregrina é merecedora de tamanha paixão.

Tinha a Douda volvido em torno os olhos, Até que os fita no gramineo assento; Estática ficou... pasma, contempla... Dói-lhe o que vê; mas admira - absorta:

De verde relva no mimoso banco

Por entre as hastezinhas entrançadas

De belas flores, que da verde cúpula

Vêm caindo ao acaso vacilantes,

Quais madeixas de um gênio da floresta;

Vê-se num abandono voluptuoso

Sentada a meditar mulher ou anjo.

O primor de um cinzel sublime fora, Se fora estátua; tão formosa é ela!... Quando póde a mudez quebrar do espanto, Torcendo as mãos, murmura a pobre Douda:

"Razão teve de amá-la! ..."

4. MACEDO, op. cit. pp. 95-96 
Um grande mistério envolve a vida de Peregrina: em completo isolamento, diz apenas amar harmonias e perfumes. A Douda, porém, sufocando todo o amor que sente pelo Trovador, interpela a jovem, acusando-a de um desprezo injusto e avisando-a do perigo que corre, por afrontar a Nebulosa, protetora do amor. Peregrina recusa-se a atendê-la, afirmando que há traição em todo amor humano, pois este fatalmente acaba, após o gozo, na indiferença e no tédio.

o Trovador que tudo ouvira escondido entre as árvores, perde a minima esperança que lhe restava. Marca, então, um encontro fatal com a Douda, na Rocha Negra, quando soar a meia-noite.

Canto IV - Nos Túmulos: num cemitério, em meio a trevas, caminha o vulto sombrio do Trovador, que se dirige ao túmulo do pai. Em prantos, o poeta fala de suas saudades, do seu desespero, de seus remorsos e aflições por ter abandonado o lar e a mãe, levando pela sua paixão infanda.

Ouvem-se passos na ermida do cemitério: é Peregrina, que vem chorando o fúnebre aniversário da morte de sua mãe. O Trovador ainda suplica seu amor, recebendo, inapelavelmente, uma recusa como resposta. Jamais e a palavra fatal, porque Peregrina teme o ardor da paixão, a dor das traições, a violêncla dos ciúmes que a arrebatariam, se ela se entregasse à : força dos sentimentos.

Aflige-me esse amor, que te desvaira:

Não to posso pagar: mas devo abrir-te

Uma vez, uma só, toda a minh'alma;

Praza ao Céu, que esse fogo, ao vê-la, acabe.

Insensível não sou! a natureza

Um coração me deu, que se arrebata

Aos impulsos de amor; se em flama ardente

Por um homem meu selo se abrasasse,

Minha paixão o mundo espantaria;

Cega, louca, em delírios me perdera.

Meu amado a seus pés cultos rendendo 
Ver-me-ia sempre em êxtases divinos. Se eu sofresse, ocultara as minhas dores. Pra não vê-lo sofrer, agonizante Rir-me soubera disfarçando a morte. Sempre a seu lado pra morrer por ele, Aos tumultos e à guerra o seguiria Tão de perto, que um golpe ambos ferisse. Eternamente unidos, nossos laços Nem a morte quebrara: se a desgraça Mo roubasse na vida, às horas mudas Da lutuosa noite a sós iria Penetrar no jazigo, erguer-lhe a campa, Tomar-lhe ao lado o meu lugar de esposa, Unir os lábios meus aos seus de gelo Fogo emprestando a seu cadáver frio, E estreitada com ele em eterno amplexo Expirar entre lágrimas e beijos.

Se em meu amor porém traída eu fosse Uma vez... meu furor... oh! nem pensá-lo! Toda a paixão se tornaria em ódio, $E$ igual a ela atroz fora a vingança! Do amante e da rival no sangue impuro Saciara um ciúme enfurecido, $\mathrm{E}$ insepultos deixando seus cadáveres Do pasto às feras, tombaria exanime Ao rebentar o coração de raiva Ao som das maldiçōos de um mundo estulto, $\mathrm{E}$ votada por Deus às negras fúrias. ${ }^{5}$

O Trovador diz-lhe que este é o sentimento a que aspira, pois é o espelho de seu próprio desejo. Peregrina, entretanto, explica-lhe por que jurara jamais amar. Ela e sua irmä gêmea eram frutos de um amor espúrio; a mãe, abandonada pelo amante, fora amaldiçoda pelo próprio pai, que nelas apenas via a marca infame da familia desonrada. A maldição

5. MACEDO, op. clt. pp. $158-160$ 
selara, para sempre o destino das três mulheres, mãe e filhas. Como consequiência, a irmã de Peregrina, também seduzida por um fidalgo libertino, antes de morrer, suplicara-lhe jamais entregar-se aos amores de um homem. A mãe de Peregrina, em mesmas circunstâncias, fizera com que ela confirmasse $o$ trágico juramento. Aquele jamais obriga-a a fugir dos homens e do amor que envenena as virgens. Assim, ela apenas procura a felicidade nas delícias do amor a Deus.

O Trovador insiste mais; ouvindo, porém, a negativa irrevogável, declara que vai matar-se. Nem isso comove a jovem: irredutivel, ela o abandona entre os túmulos, qundo surge a figura de outra mulher.

E a mãe do jovem poeta, que, abraçada a ele, conta seus sofrimentos, pedindo-lhe que volte para junto dela. O Trovador, porém, recusa 0 amor materno - apenas a morte poderá livrá-lo do desespero. Dizendo que vai lançar-se no mar, foge, enlouquecido, na escuridão.

Canto $\mathbf{v}$ - A Mãe: a mãe do Trovador decide procurar Peregrina, que reside, com sua corte de virgens, num vasto albergue entre os bosques.

Enquanto isso, Peregrina vê, em sonhos, o suicídio do Trovador. levada por uma fada terrível ao cenário da tragédia anunciada: após atravessar uma região de horrores satânicos, Peregrina paira no espaço. Do alto vê o Trovador, invocando a morte, e a figura exasperada de uma velha que implora pela salvaçāo do jovem. Milhares de anjos, entre os quais Peregrina vislumbra o rosto materno, suplicam-lhe que impeça o suicídio.

Eles e a velha em lágrimas desfeitos

O rochedo apontando à sombra falam,

Salva-o! clamando, e a sombra fica imóvel;

Vai dar o Trovador o salto horrendo,

Estrebucha de dor a Peregrina,

E à própria sombra grita - salva-o - e ainda 
A sombra não se move; ao mar se arroja

O mancebo; - maldita! - os anjos bradam,

E esse que a virgem pela mãe tomara, Voa, na queda o Trovador suspende,

Leva-o nas asas e pra o Céu remonta;

Em medonho dragão torna-se a velha,

A sombra se arremessa e a despedaça,

E como se em seu corpo os golpes fossem

Atrozes garras sente a Peregrina

Retalhando-lhe as carnes; fundo abalo

Revolve a natureza... estrondo enorme

Arrebenta; do Céu estala a abóbada,

$E$ por entre as imensas fendas jorram

Chamas em borbotões, e chovem raios:

Lua, estrelas no pélago se afundam,

E tudo horror, e horrorizada a virgem

Desperta em ânsias, arrancando um grito. 6

O sonho é interrompido com a chegada da mãe do Trovador, a qual bate à porta, clamando pela clemência de Peregrina. Após muito relutar, a moça resolve atender às súplicas da velha mulher. Partem ambas, numa corrida vertiginosa em direção ao mar, na tentativa de evitar 0 trágico desenlace. Pressentem, todavia, que chegarão tarde - a lua; sumindo-se no céu, indica que a hora fatídica tinha chegado.

Canto VI - Harpa Quebrada: O Trovador, em amargas palavras, amaldiçoa a vida, o mundo, o amor. Depois do último canto, que é uma elegia à morte e um adeus apaixonado ao instrumento de sua arte e expressão de seus mais caros sonhos, quebra a harpa.

No mar, surge, novamente, o batel: nele vem a Douda, com vestes de noiva. Ela convida o poeta a habitar, com ela, o palácio da Nebulosa. Chegara, também, para a Douda a hora derradeira: tinha recebido das fadas um apelo para

6. MACEDO, op. cit. pp. 209-210 
que fosse juntar-se a elas no reino do fundo do mar. Lamenta, entretanto, que Trovador já näo possa oferecer-lhe uma última canção, por haver quebrado sua harpa.

Lembra-lhe, porém, a necessidade de morrer, de cumprir a decisão de suicidar-se. Mostra-lhe as delícias que ambos poderảo encontrar na morte - fascina-o com sua loucura e paixão, prometendo-lhe gozos infinitos no reino marinho da Nebulosa. Abraçados, os dois se lançam nas águas, em meio a trevas e borrasca.

O Trovador atira-se nos braços,

Que the estendia a amante desvairada;

Ambos se apertam, misturando alentos,

Unem os lábios, e trocando um beijo,

Um desses beijos que uma vida pagam,

Sem que morra o pudor, delícias libam;

Mas um momento só; que delirantes

Enlaçadas as mãos, ambos correndo

A extrema fatal sobem da rocha

$\mathbf{F}$ às ondas furiosas vão lançar-se.7

Epilogo: a velha e Peregrina, que despertara tardiamente para 0 amor e 0 arrependimento, não chegam a tempo de impedir a desgraça - sobre a areia apenas encontram os restos da harpa despedaçada. A velha mãe enlouquecida pela dor, amaldiçoa a moça e tomba, sem vida, sobre a rocha.

Qual ferida de um raio, a Peregrina

Cai com os lábios de encontro à harpa quebrada.

E a velha, pobre mãe, da dor no excesso,

Sobre a rocha fatal tomba sem vida,

E aberto um golpe na rugosa fronte,

Banha o sangue materno 0 altar da morte.8

7. MACEDO, op. cit. pp. 285-286

8. MACEDO, op. cit. p. 283 : 


\section{Romantismo: a constelação edênica e o narcisismo}

A simples leitura do resumo do poema - cujo tonus de morbidez e impotente erotismo procuramos intencionalmente reproduzir - faz com que o leitor, iniciado na cosmovisäo ultra-romântica; identifique, de imediato, certas projeções arquetípicas. Tais projeçōes estão intimamente relacionadas, não só com a constelação edênica ${ }^{9}$ mas também com a inversão especular dos motivos nela representados, ou seja, a perspectiva da queda, que traduz a oscilação do espirito poético entre dois espaços: o espaço da luz e o espaço das trevas: No desenvolvimento desses pressupostos, devemos referir-nos aos motivos do eterno feminino cruel, da Grande Deusa, mãe e.criadora, e, principalmente a alegorização do esforço poético de transceder a ruptura sujeito/objeto:- que será a marca trágica do chamado mal-do-século.

A constelação edênica, tal como a concebe Phillippe Sellier, é um "ensemble permanent de représentations almantées les uries par les autres": apresenta estrelas de diferentes grandezas, porém a mais brilhante é a mulher. A mulher nua, suave e bela, que convida ao amor e aos jogos eróticos, numa atmosfera de inocência, que não é senão a representação da infência reencontrada.: Sellier refere-se a outros astros que compõem esta constelação aprazivel e estática: a terra, a vegetação, ás águas imóveis ou em leves correntezas, a luz tênue, a dança, 0 arabesco, a eterna primavera.

"Dans un tel univers, le temps suspend son vol ou volle un flux heureux sous une douce mélodie. Là ne peut subsister un homme seul: le lyrisme d'Adam, lorsque tve lui est donnée, est caractéristique de cet impératif de l'imaginaire. Narcisse se féminise, et meurt. Orphée est déchiqueté par des fèmmes jalouses. Tandis que, dans ce cadre, Vénus sortie des eaux se suffit. Pourquoi?

9. SELLIER, Phlllippe. L'évasion, Paris-Montreal, Bordas, 1971, pp. 33-36. 
L'histoire des religions permet de répondre, et en même temps d'expliquer la permanence et la solidarité de certains éléments de cette constellation. Flle constate la fréquence du motif de la Grande Déesse nue, représentée auprès d'un arbre sacré et près de sources, acompagnée d'animaux qui la servent. Dans son Traité, M. Eliade souligne que la Terre, la Végétation, les Eaux sont dans toutes les civilisations les symboles de la fecondité inépuisable, de la vie, du renouvellement (d'où les noms d'arbre de vie, de source de vie, de fontaine de jouvence). Chacune de ces réalités est liée a la Femme, "mère de tous les vivants", c'est-d̀-dire "Eve (d'aprés la Genèse, III, 20). Ainsi s'éclaire la présence, dans toutes rêveries d'ten, des ces quatres réalités: Terre-Végétation-Eaux-Femme (mère). Il s'agit d'une constellation où regne la femme." 10

Nesse domínio, pacificado, processa-se, sem fissuras, a união sujeito/objeto, a sintonia do individuo com a natureza.

Importa aqui, mais do que explorar explicações de caráter psicanalítico (o retorno ao seio materno, por exemplo) verificar o corpo de teorias que revigoram essas representações míticas. $\mathbf{E}$, ainda, a origem dessas idélas, sua evolução, a fim de que possamos compreender por que, em dado momento; 0 anelo paradisfaco de integração na mãe-natureza; a coalescência sujeito/objeto sofrem uma ruptura - o que determina 0 aparecimento das imagens triunfantes da femme fatale, da mulher implacável, tais como são analisadas por Mario Praz $" 11$ na obra de Swinburne:

"Pero la diosa Libertad adorada por el poeta no es más que una sublimación de su tipo de mujer; una divindad que no tolera freno ni leyes (hipóstasis de la mujer disoluta), fatal y cruel al exigir el sacrificio de vidas humanas (hipostasis de la algofilia)".12

10. SELLIFR, op. cit. pp. 33-34

11. PRAZ, Marlo. La carne, la muerte y el diablo (en la literatura romántica); Caracas, Monte Avila Editores, 1969

12. PRAZ, op. cit., p. 249 
Tomemos como ponto de partida para essa análise, as reflexōes sobre as analogias românticas da arte e da mente, expostas em El Espejo y La Lâmpara, de M. H. Abrams. ${ }^{13}$ Tais reflexōes remetem-nos à discussão do papel ativo ou passivo da mente criadora, ante os objetos dos sentidos. Para melhor esclarecer. a linha evolutiva da nossa análise, fixaremos o seguinte quadro:

\begin{tabular}{|c|c|c|c|}
\hline \multicolumn{2}{|c|}{ CLASSICISMO } & \multicolumn{2}{|c|}{ ROMANTI8MO } \\
\hline $\begin{array}{l}\text { Objeto da } \\
\text { Imitaglo }\end{array}$ & $\begin{array}{l}\text { Mundo das } \\
\text { Idétas }\end{array}$ & Natureza & Indlviduo \\
\hline $\begin{array}{l}\text { Imagem } \\
\text { recorrente }\end{array}$ & $\begin{array}{c}\text { espelho } \\
\text { (sujelto:objeto :: } \\
\text { reflexo:cópla) }\end{array}$ & $\begin{array}{c}\text { lâmpada } \\
\text { (sujeito:objeto :: } \\
\text { consclente:in- } \\
\text { consciente) }\end{array}$ & $\begin{array}{l}\text { espelho } \\
\text { (sujelto: para s1 } \\
\text { mesmo :: objeto: } \\
\text { subconsclente) }\end{array}$ \\
\hline $\begin{array}{l}\text { Atlvidade } \\
\text { da mente }\end{array}$ & passiva & ativa & passiva \\
\hline $\begin{array}{l}\text { Atividade } \\
\text { artística }\end{array}$ & projeção & $\begin{array}{c}\text { junçăo } \\
\text { sujelto/objeto }\end{array}$ & $\begin{array}{c}\text { disJunção } \\
\text { sujelto/objeto }\end{array}$ \\
\hline $\begin{array}{l}\text { Produto } \\
\text { artistico }\end{array}$ & $\begin{array}{l}\text { simulaçăo ou imi- } \\
\text { taçăo do objeto } \\
\text { pela razăo }\end{array}$ & $\begin{array}{l}\text { mediação consci- } \\
\text { ente / incons- } \\
\text { clente pela intui- } \\
\text { ção }\end{array}$ & $\begin{array}{l}\text { projeçōes pes- } \\
\text { soais, produtos } \\
\text { da alucinação } \\
\text { e da allenação }\end{array}$ \\
\hline
\end{tabular}

Não nos deteremos aqui na discussão das idéias platônicas e aristotélicas a respeito da atividade artística. Interessa-nos realçar a evolução do platonismo ao neoplatonismo, no que se refere ao papel da mente na atividade perceptual e verificar como essas idéias influíram no pensamento romântico.

Conforme se lê em Abrams, críticos e poetas românticos, como Coleridge, recorreram a metáforas antigas - tomadas

13. ABRAMS, M.H.. El espejo y la lámpara (teorla romántica y tradición critica acerca del hecho literario). Buenos Alres, Editorlal Nova, 1972. 
das filosofias platônica e neoplatónica - para discutirem o papel ativo ou passivo da mente na criação artística. Da clássica representação platónica, que concebe a mente como passiva, evolui-se para a proposição plotiniana da mente como "un acto y un poder que "da irradiciones de su provisión propia" a los objetos de los sentidos". 14

"Si Platón fue la fuente principal del arquetipo filosófico del reflector, Plotino fue el principal engendrador del arquetipo del proyector; $\mathrm{y}$ ambas, la teoría romántica del conocimiento $\mathrm{y}$ la teoria romantica de la poesía, pueden ser tenidas por las remotas descendientes de esa imagen-raí de la filosofia plotiniana". 15

Na fase inicial do Romantismo, predominam as imagens relativas a lâmpada, ao elemento projetor, enfim, de novas formas. A representação neoplatônica da alma como uma fonte inesgotável de formas criadoras; associa-se a perspectiva de uma interrelação - íntima, profunda - entre sujeito e objeto. Abrams cita uma passagem de Wordsworth em que - poeta expressa as sensações de uma visita aos Alpes como uma correspondência inefável entre 0 visto e 0 sentido. Torna-se absoluta a interaçã sujeito/objeto, nesse universo sem fissura. Há um fluir contínuo entre a mente e 0 objeto tomado da realidade. Assim, na visão do poeta, a corrente espiritual encontra seu análogo no fluir do rio, pois nada é senão

\section{“... but a stream}

That flowed into a kindred stream; a gale Confederate with the current of the soul..."16

Além das imagens relativas a correntes que confluem, a lampadas, que projetam formas criadoras em si mesmas, Abrams faz referência aos motivos relacionados com a imagem

14. ABRAMS, op. clt., p. 91.

15. ABRAMS, op. cit., p. 91 .

16. ABRAMS, op. cit., p. 94. 
da harpa eólia, a qual por motivos evidentes, é importante para nossa análise. Em Coleridge, M. H. Abrams mostra um exemplo da correspondência metafórica entre a harpa e a mente pensante:

"And what if all of animated nature

Be but organic harps diversely fram'd

That tremble into thought, as o'er them sweeps

Plastic and vast, one intellectual breeze,

At once the Soul of each God of all?" 17

O ato poético, portanto, resulta da interação mente/ objeto, do esforço órfico de animar o inanimado, da busca de ressonâncias e correspondência, sendo toda a atividade artística mediação e reconciliaçäo com a natureza.

"Ia razón para esta común preocupación de la filosofia de la naturaleza y del arte de comienzos del siglo XIX no es difficil de encontrar. Fue parte esencial del intento de revitalizar el universo material y mecánico que habia emergido de la filosofia de Descartes y Hobbes, y que habia sido dramatizado por las teorías de Hartley y los mecanicistas franceses de finales del signo XVIII. Fue, al mismo tiempo, un intento de sobreponerse al sentido de allenación del hombre del mundo, salvando el corte entre sujeto y objeto, entre el mundo vital, ajustado a finalidad y valioso de nuestra experiencia íntima, y el postulado mundo muerto de la extensión, la cantidad y el movimiento. Demonstrar que el hombre comparte su vida propia con la naturaleza era reanimar el universo muerto de los materialistas, y al mismo tiempo vincular de nuevo lo más eficazmente el hombre con su medio." 18

Torna-se, portanto, necessário humanizar a natureza, libertar o homem do cotidiano e da duração profana, atraves

17. ABRAMB, op. cit., p. 95.

18. ABRAMS, op, cit., p. 101. 
da imaginação e da intuição - capazes de projetar novos mundos, em que se restaure o tempo sagrado dos paraísos terrestres.

Na reação contra o materialismo e o positivismo, buscase afirmar a vida e a inteligência, o movimento mecânico do universo e a vida do homem como um todo-uno, num "intercâmbio de vida, incesante e circular, entre el alma y la naturaleza en el qué es imposible distinguir qué es 10 dado y qué 10 recibido." 19

Desses pressupostos decorrem, como se vê em Abrams, as "metáforas familiares. . 20 - relativas ao vinculo fllial entre o ser e a natureza, e as "metáforas conjugais" q1 que apóntam para "un prodigioso prothalamion que celebra el maitrimonio de la mente y la naturaleza, la consumación del matrimonio y la consiguiente creación (o procreación?) de un mundo perceptual viviente."

A busca desse todo-uno, porém, encobre a impotência de aceitar o real; o mundo tal como se apresenta aos sentidos. Evidencia-se, assim, a ruptura: instauram-se outras formas dè alienação em que se enfatizam as projeções individuais. $O$ artista refugia-se em ucronias e utopias, como única forma de escapar à trágica experiência de existir numa naturezà impassivel e desprovida de um sentido imanente.

O ultra-romantismo será a expressão da consciência da ruptura. Nessa fase, verifica-se a convergência das imagens espelho-lâmpada, refletor-projetor. A absolutização desse idealismo egocêntrico pode ser captada nos motivos relacionados com a derrota de Orfeu e com a imagem de Narciso - o arquétipo da imersão total do sujeito nas suas projeções e da perda de autonomia da realidade objetiva. Vale aqui utilizar a citação, feita por M.H. Abrams, de um ensaio de Peter Sterry:

an:

19. ABRAMS, op. cit., p. 105.

20. ABRAMS, op. cit., p. 103.

21. ABRAMS, op. cit., p. 103. 
"De tal modo es el Alma, o Espíritu de cada hombre, todo el Mundo para él. El Mundo con todas las variedades de cosas en él, su propio cuerpo con todas sus partes y cambios, son él mismo, su propia Alma o Espíritu manando de su propia fuente dentro de él mismo, en todas esas formas e imágenes de cosas que él ve, oye, huele, gusta, siente, imagina o entiende... El Alma, a menudo mirando sobre ello, como Narciso sobre su propia faz en la fuente, olvida que eso es él mismo, olvida que es la faz, la sombra y la fuente, así cae en un apasionado amor de sí mismo en su propia penumbral figura de sí mismo" 22

Através desses elementos, procuraremos definir a estrutura arquetípica de A Nebulosa, de Joaquim Manuel de Macedo - principalmente, a inversão dos elementos da constelação edênica, a perspectiva da queda, que instauram $Q$ reino da Vênus noturna.

Pode-se, desde já, concluir que, nesse poema, delineia-se um universo dominado pelo elemento feminino, ao mesmo tempo fonte de criação e elemento de destruição. $O$ amor coexiste com a morte, exalta e destrói o homem, que não tem uma função ativa. O Trovador é um Orfeu impotente ante a natureza impassivel, incapaz de animar o inanimado; e, nesse processo de inversāo, entrega-se à morte, nos braços de sua Eurídice, representada pela Douda:

A sua morte - suicídio narcísico que the abre as portas de um reino habitado só por mulheres - implica não só a anulação no objeto desejado e inacessivel, mas também a rendição a um poder feminino simbolizado pela água.

Para encerrar esta trama ide analogias, lembremo-nos de que, na interpretação psicanalítica, a água é, antes de tudo, um símbolo do inconsciente.

22. ABRAMS, op. cit., p. 92. 
3. A Estrutura Arquetípica de A Nebulosa: a experiência do limiar e 0 domínio da Vênus noturna

Tentaremos demonstrar, a seguir, que, em A Nebulosa, se processa a ruptura do já referido intercámbio da vida, entre a alma e a natureza. A constelação edênica, representação de uma unidade sem fissura, é substituida pela perspectiva do dilaceramento e da tensão entre dois domínios que, embora complementares, se opõem tragicamente. Podemos, assim, esquematizar a estrutura arquetípica do poema a partir da idéla da tensão entre dols universos opostos, a qual explicitaremos como a experiência do limiar, que leva à queda e à perda de uma unidade, antes percebida como primordial e única. Veja-se o seguinte gráfico:

dominio diurno

PEREGRINA

AR

LUZ

BOSQUE

mediaçăo: MAE (o lado noturno da existencia)

$\downarrow$

\section{o limiar}

DOUDA A ROCHA NEGRA TROVADOR dominio crepuscular

$\uparrow$

mediação: MAF (fonte da água da vida)

\begin{tabular}{|ccc|}
\hline & $\begin{array}{c}\text { dominlo noturno } \\
\text { NEBULOSA }\end{array}$ \\
AGUAS & TREVAS & MAR \\
\hline
\end{tabular}


O universo em que se move o Trovador é dominado pelo elemento feminino. Este elemento, entretanto, aparece estigmatizado pela maldição da maternidade, que, não está presente na constelação edênica.

"La femme-mère représente la fécondité, l'opulance, la maturite, la lourdeur heureuse, la tentation de l'enlisement. Or la maternité n'apparait guère dans les tedens. Ceux-ci sont peuplés des vierges qui deviennent bientôt de jeunes femmes (sauf dans le paradis de Mahomet, où les filles retrouvent sans cesse leur virginité perdue). Selon toute une tradition du christianisme, Adam et ìve, avant la "chute" (liée à la pesanteur) étaient doués de corps éthérés, presque immatériels: "Ce corps immortel était constitué par l'énergle concentrée de la lumière et des éléments, avant que ces éléments ne fussent déchirés par la malédiction" (A. Faivre. Eckartshausen et la theosophie chrétienne, Paris, 1969, p. 277). 23

A maternidade, portanto, é a maldição que separa o Trovador de Peregrina e que íŕ contribuir para o enlace do poeta com a Douda - alegoria não só da separação do Céu e da Terra, mas também do rito da fertilidade, que prescreve um estágio de sacrifício (emasculação, como no rito de Cibele); para se alcançar a essência do Homem Primordial, esposo mítico da Grande Maga, da Terra-Mãe.

Trata-se, enfim, da consciência de que "le monde est encore régi par le gouvernement des forces profondes, des impératifs dionysiaques, des impulsions telluriques." 24

Peregrina representa o mundo puro das idéias a que o Trovador nāo pode ascender, devido ao fracasso de seu "esforço órfico", que decorre da bipolaridade de sua natureza humana: de um lado, titânica e irracional; de outro, dionisíaca e imortal.

23. BELLIBR, op. clt., p. 34.

24. CaIlloIs, Roger. Mythe et Thomme, Paris, Gallimard, 1972, p. 142. 
"Los ritos órficos tenían el propósito de purificar la naturaleza humana de su elemento terrestre, reanimando en cambio la chispa proveniente del cuerpo titánico." 25

Este reencontro, porém, pressupõe a renúncia à aventura de Eros e Psiquê (a definição da personalidade na totalidade dos fenômenos psíquicos, conscientes e inconscientes). Impõe o despojamento do poder do Pai (objeto da luta dos titãs, afirmação do poder masculino) e, principalmente, a fuga da vida sensível, da paixāo, do devenir.

O artista ultra-romântico, ao reviver tais visões arquetípicas, tenta reafirmar a força criadora da mente humana, só alcançada na ruptura de uma ordem divina, na luta contra o céu de "astros fixos" (como se apresentam na constelação edênica, por exemplo) — o qual deveria ser, no ritual órfico, o objeto da busca do nous, isto é, da alma racional do homem.

$\because$ Assume-se o valor da queda, não se almeja a fixidez da pureza - transposta a "porta dos Homens", a alma humana permanece no mundo sublunar, zona intermediária, que the permite unir-se ao corpo.

"Es slempre en la Luna donde se abandona el principlo material cuando el alma purificada comienza su ascenso hacia el cielo. La Luna es la "tierra etérea", la "tierra olímpica." Es el misterioso paraje llamado las "Islas Afortunadas" o también las "Islas de los Bien-aventurados". Pero los "puros" sólo hacen escala en el satélite, pues su sítio definitivo está en la esfera de las estrellas fijas. La Luna no és mas que una etapa intermedia y necessaria, por lo que los Pitagóricos asociaban la psyche con los planetas, entre ellos la Luna, en tanto que el nous correspondía al cielo de los astros fijos". ${ }^{26}$

25. Masson, Hervé. Manual e Diccionario del esotérismo, México, Ediclones, Roca, 1875, p. 556.

26. MA8SON, op. cit., p. 663. 
A Lua, como observa Perez-Rioja 27 tem um simbolismo complexo - contrapõe-se ao mundo da luz (ao Sol), significando o reino das trevas. Identificada com a Noite, possui, ao mesmo tempo, uma significação maternal, protetora, mas perigoșa, pelo que oculta. A ela estão associadas as idéias de imaginação e de fantasia. $\mathrm{E}$, o que é mais importante, de loucura.

A união entre o Trovador e a Douda fica, desse modo, esclarecida: a expressão artística, no ultra-romantismo, origina-se do anseio de a arte ser a manifestação das mais profundas reaçōes humanas, de todas as suas potencialidades, da face oculta da alma.

Tal atitude pressupōe um ato de rebeldia, a recusa em aceitar a unipolaridade do ser e, mais ainda, a angústia diante da Natureza.

Surgem, assim, as" "siniestras representaciones de la Diosa-Madre, guardiana de los muertos y divinidad subterránea, protectora de las cosechas y del grano fértil." 28 doadora de todos os bens, mas fonte de angústia, porque revela ao homem o abismo entre a Alma do Mundo e a alma humana, entre o ser e as sensações.

O impulso erótico, transformado em desejo sem finalidade (pela impossibilidade de o desejo dar forma ao objeto de suas fantasias ou de libertar-se de seus fantasmas) não mais estabelece a harmonia entre os seres viventes, a plasmação de um universo ordenado.

Como Narciso, o Trovador mergulha no abismo de suas quimeras. Como Orfeu, preso a uma sombra inatingível, é sacrificado pela sua própria loucura.

Examinaremos, a seguir, os mitemas relacionados com essa experiência do limiar (a zona intermediária e penumbral da alucinação e da alienação) e com a Vênus noturna (representação do eterno feminino, cruel e instável) .

27. PHREZ-RIOJA, J. A. Dicclonario de símbolos y mitos, Madrid, Editorial Tecnos, 1971, p. 276.

28. MASSON, op. cit., p. 525 . 


\section{Mitemas}

\subsection{A Pedra}

O simbolismo da pedra ou das rochas aparece, em diversas mitologia, associado às idéias de permanência, solidariedade consigo mesmas; ao símbolo da firmeza e da coesão da terra em si mesma. Está, em decorrência disso, relacionado com a idéia de fundação ou de abertura, tanto nos processos cosmogônicos quanto nos ritos de iniciação.

A pedra fundamental aparece nas palavras de Cristo a Pedro ("Tu és Pedro, e sobre esta pedra edificarei minha Igreja."), simbolizando, como em outros textos, o ponto fixo, central, do universo.

"Cuando Diós cré́ el mundo - dice Rabbí Josse - lo estableció sobre siete pilares, pero nadie puede saber sobre que cosa reposan estos siete pilares, pues se trata de um misterio oculto e insondable. Fl mundo sólo comenzó a existir cuando Diós cogió una cierta piedra, que se llama "Piedra de fundación" (even schethiyah) y la lanzó al abismo (las aguas de las posibilidades universales) de suerte que allí se implantara sólidamente, para que pudiera construir-se el mundo sobre ella. Es el punto central del universo, y sobre este punto está el Santo de los Santos." 20

A pedra bruta pode ser, também, a imagem do caos primitivo que contém todas as possibilidades; nesse caos ela instaura a ordem para fundar um universo de acordo com um plano preestabelecido.

Estão aí, intimamente relacionados, os atributos principais da água e da pedra - elementos primordiais no processo cosmogônicos, representam a solidez nas vagas, no abismo; a ordem da Altura (ou Transcedência) que paira sobre as vagas, sobre 0 abismo. $O$ abismo (caos) associa-se à idéia de abertura inicial, pois é o "orifício por donde ilueven sobre el

29. MAsBON, op. cit., p. 558. 
mundo las bendiciones de arriba". ${ }^{30}$ A mitologia aquática está ligada, da mesma forma, a concepção do fluido como a totalidade de todas as virtudes, bem como de processos de ressurreição ou instaurações de outra humanidade. A imersão na água, como vimos, prende-se ao simbolismo da maternidade e da imersão no inconsciente.

Tal simbolismo, portanto, relaciona-se com a representação do limiar (entrada, começo, zona intermediária), que propomos como a imagem da fissura, da ruptura, dentro de A Nebulosa.

Nesse poema, a Rocha Negra é o ponto fixo, o umbral nebuloso, sem forma, em que se decidem os destinos das personagens. Personagens que, a princípio, pairam entre dois espaços, o terrestre e o marinho, para se lançarem, definitivamente, no domínio das trevas e das águas.

Dizem que ali na turva penha imensa $\mathrm{Em}$ velhas eras se acoutava insana Mulher sabida em mágicas tremendas, Que ensinam maus espíritos; formosa, Inda aos cem anos moça como aos vinte, Vé-la um momento era adorá-la sempre; E amá-la eterno perdimento d'alma. Gênio das trevas, só da lua amiga, Fugia à luz do sol: mercê de encantos, Durante a noite mistica pairava No espaço, em torno à rocha densa nuvem, Em cujo seio toda se embebia, Mal se abriam no céu rosas d'aurora; Chamavam-na por isso a Nebulosa.

Gênio das trevas embora, a Nebulosa é como Lúcifer, o mais belo e mais brilhante dos anjos, a portadora da luz - de uma nova forma de conhecimento, além do consciente

30. MASBON, op. cit., p. 652. 
e da lucidez diurna. Lançada no mar, em virtude de castigo divino, a formosa feiticeira instaura um novo reino, tendo como aliadas a lua $\mathrm{e}$ as fadas. Nesse universo encantador nāo entram os homens - como diz, a princípio, a Douda: nem o Trovador que é "belo e pálido" como a Nebulosa. Posteriormente, ele próprio será iniciado no reino marinho.

A pedra é, nas várias mitologias, o símbolo da esterilidade - tal analogia torna mais clara a sua função no poema analisado. Torna-se, em conclusão, a imagem de um universo que perdeu todas as suas potencialidades, e de cuja queda deve brotar uma ordem nova. Representa, no plano literário, o limiar da atividade artística, colocada entre as representações da consciência e da inconsciência. o umbral, a zona divisória, tal como aparece na mitologia clássica, em que a Terra foi representada por uma figura de mulher sentada numa rocha - rocha sobre as águas, sobre o abismo. Em A Nebulosa temos, pois, a alegoria da transubstanciação da matéria organizada (o cosmo) no caos primordial, na água que é o princípio de todas as coisas (como a aqua permanens dos alquimistas). A vida, a maternidade, passam a fluir das trevas e da experiência da queda. Queda que é imersão na substância primordial, nas origens, no inconsciente. Logo, uma inversão edênica - o Verbo divino dá forma ao nada, ao abismo. O esquecimento (mergulho no inconsciente) das palavras mágicas dá, à Nebulosa, tanto o poder de recriar o uniforme, quanto a plena libertação do poder masculino, divino e diurno. Universo espelhado e invertido, propiciará ao artista, contemplador e rebelde, a sua individuação, o encontro consigo mesmo não mais criatura imagem e semelhança da Idéia divina, mas criador dotado de poderes divinos.

Tal processo implica a "feminização" do Trovador no sentido de que, como no ritual dionisíaco, ele encontrará, no reino da Nebulosa, a complementaridade que the é negada no albergue da Peregrina:

"Dionysos suele ser representado con un aspecto feminoide lo que, sumado a las caracteristicas anteriores, convierte 
a este dios en una especie de personaje andrógino comparable al Hombre Primordial de las otras tradiciones". 31

Segundo os Pitagóricos, há uma oposição radical entre a ordem do mundo celeste e a do mundo sublunar - neste reinam o acidental, o acaso, o capricho, e todos os corpos são mistos, sofrendo alterações de toda a ordem. No entanto, para a sensibilidade ultra-romântica, somente o mundo sublunar, na sua irracionalidade, permitirá o desenvolvimento de todas as potencialidades humanas.

A morbidez ultra-romântica e adolescente, agradavam esses impulsos irracionais e interditos. Veja-se o ensaio de Mário de Andrade, Amor e Medo, sobre os cacoetes românticos. Embora o ensaísta realce a frustração sexual dos autores analisados, está referindo-se, efetivamente, à revivescência da androginia como representação arquetíplca da busca de reintegração no eterno feminino, passivo e maternal, que reinstaure a unidade do Fomem primordial:

"Mais importante ainda é, no sonho de Macário, a mulher-anjo-homem assexuado que Satan explica assim: "Era um anjo. Há cinco mil anos que ela tem o corpo da mulher e o anátema duma virgindade eterna. Tem todas as sedes, todos os apetites lascivos, mas não póde amar. Todos aqueles em que ela toca se gelam. Repousou o seu seio, roçou suas faces em muitas virgens e prostitutas, em muitos velhos e crianças, bateu em todas as portas da criação, estendeu-se em todos os leitos e com ela o silêncio... Essa estátua ambulante é quem murcha as flores, quem desfolha o outono, quem amortalha as esperanças". "Quem é?", Macário pergunta. Mas Satan muda de conversa." 32

Retomando o motivo da pedra, devemos lembrar-nos de que ela possui o dom não apenas de transubstanciar (os metais ou a natureza, como a Pedra Filosofal), mas, ainda, 0

31. MASSON, op. cit., p. 527.

32. ANDRADE, Márlo. Aspectos da Literatura Brasileira; São Paulo, Martins; Brasilla, INL, 1972, p. 229. 
de conferir ao homem o domínio de toda a matéria. Não se trata, apenas, de um processo de sublimação da natureza humana, que promova sua elevação ao plano espiritual. Trata-se de reintegrá-la, em sua plenitude, no plano do Alto e do Baixo - experiência de Lúcifer, noivado do Amor e da Morte.

Para completar essas relações, observemos que no mito de Ceres ou Deméter, a deusa das terras cultivadas vai em busca da filha Perséfone, raptada por Plutão, deus dos infernos. Impossibilitada de reaver a filha, a deusa irrita-se: assola toda a terra com uma terrivel esterilidade e, em Elêusis, transfigurada numa velha, assentou-se sobre uma pedra que recebeu o nome de "Pedra sem Alegria".

Cibele, a Mãe dos deuses ou a Grande Mãe, era representada por uma pedra negra, provavelmente um aerólito.

Reunem-se aí os motivos da natureza despojada dos frutos da maternidade e do valor sagrado da pedra que, segundo Mircea Eliade, ${ }^{33}$ provém do fato de que a pedra ou uma rocha imitam algo, porque procedem de outro lugar - isto é, são projeções do poder criador, da fundamentação dos processos cosmogônicos.

\subsection{A Harpa}

A harpa, conforme se lê no Dicionário de Símbolos y Mitos, de Perez-Rioja, é comumente identificada com o cavalo branco e com a escada mistica. Desse modo, associa-se à idéla de uma ponte entre o mundo terrestre e o espiritual. Segundo Schneider, citado nesse mesmo dicionário, 0 animalsímbolo da harpa é o cisne:

"퍼 cisne-arpa, puesto entre agua e fuego, melancolía y pasión, sacrificio de si mismo y purificación, representa el camino de la intuición, de la vida afectiva, del arte trágico y del martirio; el símbolo del cisne mortuorio es la espiral".

33. PEREZ-RIOJA, op. cit., pp. 351-352.

34. PEREZ-RIOJA, op. cit., pp. 131-132. 
Em A Nebulosa, é evidente esse simbolismo: através de seus cantos, o Trovador procura ascender até Peregrina. Essa ascensão, entretanto, é frustrada: a mulher amada se nega ao amor, ao impulso erótico. interessante observar que a Douda compreende o acento lírico e erótico da arte do Trovador; somente ela, arrebatada pela loucura da paixão, identifica-se com a harpa, chamando-a de amor que fala:
"Mal escolhido... não me agrada, "Não lhe exprime a doçura; ouve mancebo, "Vamos dar-lhe outro nome; d'ora avante "Chamá-la-emos nós - amor que fala. Faze-a cantar..." 35

Essa designação leva-nos a relacionar, imediatamente, a inspiração poética com frato. Erato, cujo nome se prende a Eros, é a musa que preside a poesia lírica amorosa, tendo por atributo uma harpa ou uma lira.

Entre as metáforas da expressão romântica, com relação a poesia e a arte, Abrams coloca a harpa eólia, instrumento fantástico cujas várias cordas produziam sons maravilhosos, quando tocadas pelo vento. Ela é o símbolo da "interacción, el efecto combinado de lo interno e do externo, la mente y el objeto, la pasión y las percepciones de los sentidos." 36

A reiteração desse motivo reflete, conforme Abrams, a preocupação primordial dos artistas e teóricos românticos: modificar o material obtido pelos sentidos, sem alterar a fidelidade à natureza; animar o inanimado; preencher o vácuo entre o sujeito e 0 objeto. $E$, enfim, a ânsia de escapar à cisão, que leva o artista a criar atê mesmo o que não existe.

A título de ilustração, vejamos alguns trechos da poesia de Gonçalves Dias, em que é obsessiva a imagem da harpa.

35. MACEDO. A Nebulosa, Rio de Janeiro, H. Garnier LivrelroEditor, s.d., p. 42.

36. ABRAMS, op. cit., p. 79. 
"Então corre o meu pranto muito e muito Sobre as úmidas cordas de minha Harpa, Que não ressoam;

Não choro os mortos, năo; choro os meus dias, Tão sentidos, tão longos, tão amargos,

Que em vão se escoam.

Quem me dera ser como eles!

Quem me dera descansar!

Nesse pobre cemitério

Quem me dera o meu lugar, E co'os sons das Harpas d'anjos

Da minha Harpa os sons casar

\section{A Minha Musa 37}

"Que triste que é neste mundo

"O fado dum Trovador!

"Pesar lhe dá sua Lira,

"Dá-lhe pesar seu amor!"

$\mathrm{E}$ o Trovador nesse ponto

A corda extrema arrancou;

E num marco do caminho

A Lira quebrou:

Ninguém mais a voz sentida

Do Trovador escutou!

0 Trovador 38

Mas quem na ouvira conversar de amores,

Trouxera n'alma como uma harpa eblla,

Dia e noite vibrando,

Como um cantar dos anjos

No coração a estremecer-lhe as fibras!

$$
\text { A Sua Voz } 39
$$

37. GONÇalves DIAs, Antônio. Poesia completa e Prosa escohida, Rlo de Janelro, Aguilar, pp. 124-125.

38. GONCALVES DIAS, op. cit., p. 138.

39. GONÇALVES DIAB, op. cit.,.p. 277. 
Como Orfeu, com sua lira, o poeta intenta domesticar a natureza indomável, acalmar os ventos, alterar o fluir dos rios; enfim, dominar o fluxo da vida e do tempo. Sua meta é o universo ordenado, como no tden, em que a eternidade supera a morte e o amor é fonte da eterna juventude. Nesse sentido, Orfeu é a antítese de Circe, arquétipo da femme fatale, que transforma os homens em animais, envenenandoos com a sua paixão.

Em A Nebulosa, os mitos de Orfeu e Circé estão, evidentemente relacionados, pois referem-se à experiência do limiar e da cisão entre o céu e a terra. Tal experiência, contudo, culmina com a vitória da vênus noturna, da beleza medusina - ao ver-lhe negada a iniciação em um plano superior e místico, o Trovador entrega-se à conjuração das forças indômitas da natureza. A ênfase dada ao elemento mágico é reflexo dó sentimento de impotência e da anulação do humano sublimado:

"Os iniciados em mistério não necessitavam rezar para obter os favores da divindade: pela iniciação os deuses viamse constrangidos a atender os desejos dos mortais.

A Magia nasceu dessa idéia de obrigar as forças divinas ou super-humanas a conceder aos homens tudo que eles quisessem." 40

\subsection{Beatriz e Circe: projeção da algofilia romântica}

Os objetos do desejo do Trovador estão simbolizados por figuras femininas, cujos nomes marcam a intangibilidade de suas existências. São projeções quiméricas, apenas alcançadas pela mediação do delírio ou da loucura. Peregrina e Nebulosa são pólos opostos e complementares, representando o eterno feminino cruel - o motivo da belle dame sans merci, da feminilidade prepotente e desumana, do amor sublime e

40. SPALDING, Tassilo Orpheu. Deuses e herbis da antiglldade Clássica, såo Paulo; Cultrix/MEC, 1974, p.' 285. 
irrealizável. A volúpia da dor, tanto dos místicos quanto dos rebeldes, configura-se nessa polarização mediatizada pelo delírio.

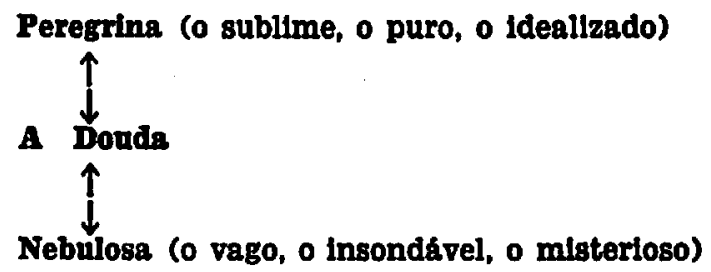

Seus arquétípos são Beatriz e Circe: "Los dos extremos de la mujer - señala Papini - se llaman Circe e Beatriz: Circe, cuando el hombre está dominado por los sentidos; Beatriz, cuando el hombre domina con la poesia" 41

Peregrina, como Beatriz, representa a mais sublime mitificação da mulher amada. O próprio nome acentua sua presença incorpórea, sombra de um mundo ideal, necessário e inatingfvel. Mundo em que a maternidade é renegada (veja-se a figuração da Mãe no poema), pois não se procura por uma mulher viva e palpitante. O elemento feminino é, como explica Perez-Rloja, sempre "la nebulosa idealizada de la mujer soñada."

Tal incorporeidade - sublime e cruel - é denunciada nas palavras da Douda à Nebulosa:

"Não és mulher, não és! no pelto aninhas

De fera um coração. Treme! a vingança

Das fadas é cruel. A Nebulosa

Protege 0 amor, e a ingratidão castiga.

Gênios do ar, os silfos invisiveis

Por toda parte vagam; treme deles!

Sabes acaso como os sllfos nascem?...

Não sabes o que são?... negros perjúrios,

41. PEREZ-RIOJA, op. clt., pp. 93-94, 129. 
Falsos votos de amor, sacras promessas, Que as mulheres volúveis quebram, mentem, Em silfos se transformam... ah! são tantos!... Tantos já, que invisíveis a não serem, $O$ sol encobriram. Seu destino t pelo espaço errar, amor vingando." 12

A ausência de coalescência entre sujelto e objeto leva à criação dessas figuras que apenas refletem, como analisa Mario Praz, em seu magnífico trabalho, o sadismo que invade todo o universo, a muda e melancólica luxúria, a sensualidade delictuosa - expressões da tensão entre a sensualidade e a fecundidade insaciáveis e a esterilidade triunfante.

Essas figurações possuem atributos comuns - são pálldas e venenosas, esplêndidas e estéreis, amargas e ternas, atrozes e lascivas. Filhas da Morte e de Priapo, segundo Praz, dão voz ao anelo de profanação dos vínculos mais sagrados, para se alcançar novamente a vida na sua plenitude primitiva e dominar a morte e sua corrupção. A beleza medusina é, portanto, uma projeção de sexualidade impotente e de mórbida sensualidade - "el movimiento originario de la inspiración está en la vaga ansia de un altísimo ideal y en la desesperación de no haberlo podido alcanzar". 4

Em A Nebulosa, encontra-se aquela similitude, analisada por Mario Praz, entre o místico e o exótico: ambos são fenomenos de transferência, no tempo e no espaço, de frustrações sexuais; essas projeções do desejo insatisfeito expressam-se através de estimulaçōes mórbidas (o êxtase místico, o ópio, a flagelaçāo, mental ou física, fazem parte dessas estimulações perversas) - para se viver única e exclusivamente do sonho e do delírio.

Assim, as figuras femininas do poema de Joaquim Manuel de Macedo são representaçōes da castidade mortífera, da be-

42. MACEDO, edlçăo de 1857 , p. 129.

43. PRAZ, op. c1t., pp. 283-284. 
leza dissoluta, que realçam tanto a passividade, quanto 0 desejo de rebelião do homem, contra Deus e contra a natureza. Póde-se dizer, de acordo com o que Mario Praz escreve a respeito de D'Annunzio, que são a figuração, não apenas da mulher-vampiro, mas do feminino que reúne em si toda a experiência sensual do mundo. 44

Essas imagens da "Mater Dolorosa e da Mater Triumphalis", da beleza frigida, da mulher-sereia, vampiro e feiticeira estão, em conclusão, relacionadas com o entrelaçamento da sensualidade e da morte, com o desejo de dar vida à natureza, através da voluptuosidade, e tudo isso, nada mais é do que a consciência, tornada moda e doutrina, de que "el delito y la destrucción" são "leyes universales de la naturaleza". $45 \mathrm{E}$ há, nessa ânsịa de delito e de destruição, a mesma ousadia titânica - que transparece nos textos sádicos de Swinburne - de roubar a centelha de qualquer poder divino, para reanimar a natureza corrompida e insensivel:

"Si un hombre pudiese hacer esto, si él pudiese entorpecer el curso de las estrellas y alterar el tiempo de las mareas; si pudiese cambiar los modos del mundo y hallar la sede de la vida para destruirla; si pudiese entrar en el cielo y contaminarlo, en el infierno y leberarlo de la sujeción; si pudiese derribar el sol para consumir la tierra y ordenar a la luna que esparza veneno y fuego en el aire, si pudiese matar el fruto en la semilla $y$ corroer la boca del infante con la leche de su madre; entonces sí podria decir que ha pecado $y$ que ha causado mal a la naturaleza. Y más aún, ni siquiera entonces: porque la naturaleza vería todo eso de bien grado, para poder crear um mundo de nuevas cosas; porque ella está cansada de la vida antigua $(\ldots)^{46}$

44. PRAZ, op. cit., p. 263.

45. PRAZ, op. cit., p. 236.

46. PRAZ, op. cit., p. 237. 
Mas não são criações românticas essas projeçōes da algofilia - em todas as mitologias, surgem alegorias do arquétipo da beleza divina e destruidora. Vejamos algumas dessas representações.

Na mitologia clássica, encontramos Circe, fillha do Dia e da Noite, célebre pela formosura e por seus prodigiosos venenos. Desencadeava os ventos, os granizos e as tempestades. E, segundo alguns analistas, a personificação de um estetismo superior, em virtude do poder encantador e terrivel de sua magia. Assim como a Nebulosa se prende à representação de Circe ou de Hécate (também divindade de significado lunar, símbolo da mãe terrível e devoradora), a Douda, sua intermediária, associa-se à representação da sereia, do canto que fascina os homens e do ruido melodioso das ondas ao quebrarem-se nas rochas.

A mitologia nórdica nos oferece um exemplar magnifico da sereia ou de Circe - isto é, da beleza sedutora, envolta em mistérios mágicos, que faz os homens naufragarem. E Lorelai, tal como aparece na criação de Heine, que conhecemos através de tradução de João Ribeiro:

"Eu não sei qual o sentido Dessa tristeza em que estou.

Úm conto, há tempo ouvido,

Da morte não me passou.

"I fresca a brisa. Anoitece.

. . : . . . Vai o Reno manso, a flux;

Ao sol-posto resplandece

O cimo da rocha em luz,

Vê-se bela, reclinada, Lorelai, sobre o arrebol, $\mathbf{E}$ alisa a trança doưrada Dos seus cabelos de sol. 
Ao mover o pente de ouro, Canta a fada uma cancão... Oh! na voz desse tesouro Que melodias estãol

Passa a barqueiro nas águas $\mathrm{E}$, emberecido de a ouvir, Năo sente o risco das fragas; Olha p'ro céu, a sorrir.

Devora-o a vaga inimiga, Naufraga o barco, lá val... Por causa dessa cantiga, Por causa de Lorelai."

\section{Conclusão:}

Outros motivos arquetípicos podem ser analisados em A Nebulosa, como o do espelho, o da nave, o da sombra, o do nome oculto. Mas acreditamos termos apontado os principais. Talvez tenhamos ido, como sapateiro mouco, além das chinelas, no impulso criativo a que o tema do trabalho nos levou. Entretanto, quais indagaçōes têm feito os homens, maiores do que essas, sobre o mistério de ser e amar, de existir e morrer? Resta sempre, no silêncio da vida e no vazio da morte, o monólogo - incómodo e eterno - de um Hamlet insepulto.

ENTRETANTO O BOL ENTRARA NO ZODIACO, ANUNCIANDO A MULHER DE ABRIL. DAO-NA TAMBAM POR MORTA, INFELIZ E LOUCA, COROADA DE LIANAS E FLORES BILVESTRES, E ASSIM ME RETIRAM TUDO QUANTO NUNCA FOI MEU. CHEGO AO LIMITE MAIS EXTREMO E DOLOROSO, AO LIMTAR DO BILENCIO QUE ME RESTA, DE OLHOS SECOS E NfTIDOS COMO CICATRIZES. PARA TODO ESTE FRIO TRAGO, NO PUNHO CERRADO, DEZ MINUTOS DE SOL E, DENTRO DE MIM. UM CADAVER INSEPULTO QUE RESPIRA INCOMODAMENTE. E, RUTILO E ACERADO QUAL ALGIDO LUME, O AMOR DAS FACAS. HA UM TUMULTO DE FANFARRAS AO LONGE. DORMIREI ENFIM.

RUI KNOPFH - OUTRO MONOLOGO DE FAMLET 